Please do not remove this page

RMIT

UNIVERSITY

\title{
Good practice groundwork: Managing initial meetings with higher degree research students
}

Eshtiaghi, Nicky; Robertson, Shanthi; Warren-Myers, Georgia

https://researchrepository.rmit.edu.au/esploro/outputs/9921858511001341/filesAndLinks?institution=61RMIT_INST\&index=null

Eshtiaghi, N., Robertson, S., \& Warren-Myers, G. (2012). Good practice groundwork: Managing initial meetings with higher degree research students. Education for Chemical Engineers Part D, 7(4), e196-e202. https://doi.org/10.1016/j.ece.2012.08.003

Document Version: Accepted Manuscript

Published Version: https://doi.org/10.1016/j.ece.2012.08.003

Repository homepage: https://researchrepository.rmit.edu.au

(c) 2012 The Institution of Chemical Engineers. Published by Elsevier B.V. All rights reserved.

Downloaded On 2023/04/26 20:54:10 +1000 
Thank you for downloading this document from the RMIT Research Repository.

The RMIT Research Repository is an open access database showcasing the research outputs of RMIT University researchers.

RMIT Research Repository: http://researchbank.rmit.edu.au/

\section{Citation:}

Eshtiaghi, N, Robertson, S and Warren-Myers, G 2012, 'Good practice groundwork: Managing initial meetings with higher degree research students', Education for Chemical Engineers Part D, vol. 7, no. 4, pp. e196-e202.

See this record in the RMIT Research Repository at: http://researchbank.rmit.edu.au/view/rmit:22154

Version: Accepted Manuscript

Copyright Statement: (c) 2012 The Institution of Chemical Engineers. Published by Elsevier B.V. All rights reserved.

Link to Published Version:

http://dx.doi.org/10.1016/j.ece.2012.08.003

\section{PLEASE DO NOT REMOVE THIS PAGE}




\title{
Good Practice Groundwork: Managing Initial Meetings with Higher
}

\section{Degree Research Students}

\author{
Nicky Eshtiaghi $^{*}$, Shanthi Robertson ${ }^{2}$, Georgia Warren-Myers $^{3}$ \\ $1^{*}$ corresponding author-School of Civil, Environmental and Chemical Engineering, RMIT University, Victoria, Australia, 3001, \\ nicky.eshtiaghi@rmit.edu.au \\ 2- School of Global Studies, Social Science \& Planning, RMIT University, Victoria, Australia, 3001, shanthi.robertson@rmit.edu.au \\ 3- Faculty of Business and Law, Deakin University, Melbourne, Victoria, Australia, 3025, g.warrenmyers@deakin.edu.au
}

\section{Abstract}

Effective supervision is a critical factor in the successful completion of higher degree research (HDR) students. The supervision of a HDR project incorporates a range of issues beyond the research activities; it includes professional development, strategic planning, basic administration, meeting deadlines, quality assurance and managing stakeholder expectations. Supervising a doctoral student is a complex task; arguably, it is the most complex level of teaching in higher education. This paper argues that initial meetings with students set the tone for the continuation of the supervisory relationship. The establishment of rapport, negotiation of expectations, and initial analysis of the student's needs are crucial first steps to successful candidature. This paper reviews literatures on supervisory practice in an interdisciplinary context in order to develop a comprehensive best practice strategy for the first supervisory meetings with a higher degree research (HDR) student. Rather than a prescribed formula for structuring the meeting, this paper indentifies core areas that need to be addressed, which can be adapted by novice and experienced supervisors to cater to their own and their students' contexts. Brief lists of 'guiding questions' are provided in each section, not as prescriptive tools, but as launching points from which mutual negotiations between supervisor and student can develop.

Keywords: postgraduate research, postgraduate supervision, research supervision, role of supervisor, higher degree research 


\section{Introduction}

Effective supervision is a critical factor in successful completion of higher degrees by research (Latona and Browne 2001; Pearson and Kayrooz 2004). Research differs from traditional undergraduate education, as undergraduate education is often seen as establishing and facilitating deeper learning of a discipline. Whereas research is an experiential form of learning, where students learn to question and develop their own ideas, manage their project, and write about it usually in the form of a thesis, and in its completion they are given licence to conduct independent research (Pearson and Kayrooz 2004; Cullen et al. 1994; Pearson 1996; Pearson and Brew 2002). Supervision still uses the fundamentals of good teaching praxis and pedagogies, in the form of concern, interest in progress and the provision of timely and thoughtful feedback (James and Baldwin 1999). The relationship between student and supervisor is fundamental to ensure a productive and successful $\mathrm{PhD}$ or Masters degree and the foundations of this relationship are built from the first meetings. It is important, therefore, to establish a solid and viable beginning to this relationship which can be further developed (Moltschaniwskyj and Moltschaniwskyj 2007).To ensure a quality relationship and to enable a stronger likelihood of completion, the establishment of mutual understanding and rapport between the student and the supervisor in the early stages of the candidature (Thompson 2008) is crucial.

In light of the importance of this foundational interaction between supervisor and student, this paper uses a critical engagement with existing literature on pedagogies of supervision to develop a framework of best practice for initial supervision meetings. The framework incorporates both pragmatic tasks of strategic planning for the candidature, as well as the crucial 'relationship work' required to build the foundations of what is one of the most intimate and ongoing pedagogical and social relationships. The establishment of boundaries and expectations are framed as a series of 'negotiations' in which both the supervisor and the student are active participants in reaching mutual agreements in core areas such as 
expectations of roles and responsibilities and discussions about number of papers and possibly on authorship. Critical reflection on the part of the supervisor is also acknowledged as an important part of the process. The best practice framework thus consists of several core processes: the establishment of rapport; analysis of the student's needs; project planning; negotiation of expectations; and supervisory reflection. At certain points, key questions for discussion between supervisor and student are raised as a guide as to how these processes could be discussed. This paper is designed to provide a reflective best practice framework, grounded in the current literature, which can be utilised by novice supervisors and supervisors who are re-skilling or refreshing their practice.

\section{The establishment of rapport}

The early stages of supervision are vital to establishing mutual understanding and rapport, factors that contribute to the quality of the relationship and the likelihood of successful completion (Thompson 2008). It is of particular importance that the personal ethics and interpersonal working patterns of the supervisor are aligned with the student (Ives and Rowley 2005). In essence, ensuring a connection or level of understanding between the student and supervisor at a preliminary stage is important in the development of the longer term relationship. This is, of course, student dependent, and the type of relationship may vary significantly from student to student. HDR students will come from diverse backgrounds and bring different experiences to the relationship. Grant (2000) establishes that the supervisory relationship is one of unusual intimacy and intensity, and Johnson et al. (2000) note the largely private and interpersonal nature of supervision as a pedagogical practice. Many researchers have also noted how gender, class and cultural difference can affect communication between student and supervisor (Over et al. 1990; Leonard, 1997; Gundara, 1997; Grant 2000; Johnson et al. 2000). Thus, understanding a new student's linguistic, cultural, familial, professional and educational contexts and experiences will be key to understanding their needs and to connect with them personally in an appropriate way. This 
will provide the foundation for the development of a long-term productive relationship between the student and supervisor.

Conrad (2007) makes a persuasive argument for 'mateship' as a visible feature within the graduate research experience. It is important to clarify the role of $\mathrm{PhD}$ student as a colleague in academia rather than as an assistant to the supervisor (Moltschaniwskyj and Moltschaniwskyj 2007; Leonard 2001). Therefore, it is the role of the supervisor to ensure the student feels welcome in the academic environment; this is often helped by University or Faculty inductions, but can be further facilitated by the supervisor introducing student to staff, in particular academic, administrative and technical staff who will provide support to the student during their candidature (Moltschaniwskyj and Moltschaniwskyj 2007). This is also a means to establish the student early on in community of practice, or, in Conrad's (2007) terms, of mateship, by building them into a network of support. Research by Deem and Brehony (2000) has conclusively shown that access to a research culture is extremely significant to the development of doctoral scholars into autonomous researchers.

How individual supervisors communicate their supportive role and work to establish rapport will vary based on their individual personality and approach. What is important here, however, is that the intention to create an atmosphere of support and collegiality is foremost in the supervisor's mind for the first meeting. This is particularly important given the power differentials inherent in the relationship and the fact that the first meeting may be a cause of apprehension or anxiety for the student.

An ethic of care is also a significant factor here. Early 'relationship work' should promote a caring, mentoring and coaching approach toward the student; however, the student also needs to feel confident that if problems arise, either of an academic, personal, cultural, racial or ethical nature, that the supervisor is there for them and are conscious of their role as mentor 
and coach (James and Baldwin 1999). The relationship with a student is likely to be very different to an undergraduate student, and the emotional intelligence and flexibility of both the supervisor and the student is fundamental to successful completion. Should this fail on either's behalf - the student or the supervisor - this failure may lead to poor outcomes for the student (Wisker et al. 2003; Taylor and Beasley 2005).

It is not expected that a strong relationship will develop in the first meeting. However, the rapport developed during that first meeting will set the scene for future development of a relationship and the ability of the supervisor to motivate, encourage, enthuse, and offer support but at the same time provide productive feedback and criticism (Lee 2008; Ives and Rowley 2005). If there is panel supervision, defining the role and the contribution of each supervisor in panel supervision from outset is important although the formal process of supervision may rely largely on a relationship with a primary supervisor. But this will make it clear for students that co-supervisors have some shared responsibilities for them (Malfroy, 2005). Transparent work load agreement can ensure the regularity of meetings that may be needed to ensure completion (Buttery et al., 2005). Outset agreement will also help students understand whether this is only corporate game and the second supervisor has no real interference in the thesis and the only the active supervisor will be responsible for the project. Furthermore, initial agreement on definition of high productivity, and views about scholastic activity and research methodology and completion time frame will ensure the development of harmony and trust between panel members which then do not confuse student with not in tune message (Buttery et al., 2005). The development of a harmonious relationship among the panel supervisors and students is a prerequisite to student satisfaction. Early on discussion around provision of online relationships either through teleconferencing, blog or other types of electronic communication and how often it should happen will improve supervisory process while one supervisor will be away for a short or extended period of time (Malfroy, 2005). 
In this first meeting, the student will be also analysing the interest, care and support the supervisor shows in the student themselves and their research (Lee 2008). The student wants to ensure that the supervisor is showing interest in them and their proposed work and has the potential to provide a mentoring role that will ensure successful completion of the candidature. It is important to note that not all of the following discussion themes will be relevant to each student - these will vary depending on whether students are local or international, and on the cultural context.

Below we list some discussion themes that may be useful in guiding and establishing rapport between student and supervisors.

- The student's academic and professional background

- The student's motivation to undertake the doctorate

- The student's external work and personal commitments

- The supervisor's academic background, current interests and projects and how they connect with the proposed project

- The student's position in the research group where their project is part of a larger programme

- The health and safety rules, attitudes regarding acceptable behaviour and bullying, etc.

\section{Needs analysis}

The supervisor's responsibility during the first meeting is to ascertain the abilities and capabilities of the student to undertake the research. This assessment is not only an academic analysis, but includes examining motivation, commitment, expectations, working and learning styles, and whether assistance will be required to develop further skills to be able to progress through the candidature. This is especially important due to the diverse disciplinary, linguistic and academic backgrounds of students. Students from a non-English speaking background, students returning to study after a long break, or those shifting into new disciplinary contexts will have diverse and specific needs in terms of the skills they need to develop and the kind of support they will need in order to develop further. As such, the needs analysis, whether 
conducted formally or informally, is linked explicitly to 'work relationship': the supervisor must understand the student's personal and academic context in order to understand their needs. Needs beyond the successful completion of the dissertation will also have to be taken into account during these conversations. Short-term motives as well as longer-term career motives are significant to the early stages of candidature (Tenant and Roberts 2007). Furthermore, analysing the facilities and resources that may be required to undertake the research is also required.

Zuber-Skerritt (1996) argues for the systematic integration and development of student research skills in graduate programs, and outlines a model for doing so that begins with identifying student problems and the gaps between their needs and institutional expectations. James and Baldwin (1999) also suggest that the supervisor needs to understand the limitations of the student's knowledge of the theoretical base and methodological procedures as well as the level of technical, computing and writing skills. McCormack et al. (2006) prescribe a fairly detailed process to manage a learning needs analysis, with specific questions and prompts which are designed to help new students to recognise their existing academic, workplace and personal skills; take responsibility for and control of their own learning through self-identification of their learning needs; develop their own plan for candidature; and identify sources, support and strategies to achieve goals. This involves the steps of developing a needs analysis, a competency matrix, and an individual learning plan. However, while undoubtedly valuable, prescriptive ways of conducting a needs analysis which involve written answers to questions and filling in long matrices of capabilities might seem arduous and unnecessary for some students, particularly those with a significant prior research experience. Conversely, a needs analysis can occur in a dialogue that stems naturally from the 'getting to know you' stage. As students may need some time to reflect on their capabilities and needs prior to the initial meeting, a preceding email asking them to think specifically about their needs and expectations may be part of a good practice strategy. It is also worth noting here 
that students should understand that learning plans are not static and immutable, but are rather:-

"living documents that should be reviewed and updated on a regular basis. The direction of research projects change frequently and modifying the learning plan to accommodate those changes and the different demands they place on you is in itself an essential generic skill to acquire” (McCormack et al. 2006, 85).

The following guiding questions can be adapted as part of a best practice approach to both the pre-meeting email and the meeting itself. Although some of these questions should be investigated before starting the candidacy, reinvestigating these matters could bring out important issues that may have been previously neglected:

- What research experience do you have and how does it relate to the proposed project?

- What is the longest piece of academic writing you have previously completed?

- How long have you been outside of formal study?

- What aspects of research/studying do you most enjoy?

- What aspects of research/studying do you find most difficult?

- What skills do you think you bring to the project?

- What skills do you think you need to improve or gain in order to complete the project?

\section{Project planning and project clarification}

Mapping out the research plan and how the student's ideas are forming and what their expectations are for the PhD project over the next few years is also important to successful completion. This has often taken the form of discussions around key milestones during the progress of the $\mathrm{PhD}$ and is frequently dictated by requirements of the University or Faculty, for example: confirmation, progress reports etc. Breaking down the time line and goals over the three years with the student to discuss milestones and management of what's expected at those milestones helps to develop a structure to the overall $\mathrm{PhD}$ period. Project planning 
processes are also directly linked to the needs analysis process, as the skills or knowledge gaps that have been identified need to be integrated into the project plan. For example, if the student needs training in particular software for data analysis, this must be completed before the student reaches that stage of the project requiring those skills.

Once the process has been discussed the topic or research area needs to be clarified. By brainstorming and working with the student the topic can be honed and the ideas consolidated in order to clearly portray the student's knowledge of concepts and existing knowledge. It is good that sometimes let students fail to ensure they learn from that process and supervisors not inhibiting their learning process. In order to develop student's research proposal, the following discussion themes are helpful:

- Identifying the research questions and interrogating them from several points of view

- Identifying sub-questions related to the research questions

- Operationalizing key concepts from the research questions

- Considering where the proposal fits in terms of literature that the student has already read and identifying avenues for further reading

- Identifying relevant theoretical frameworks and models

- Identifying proposed methods and checking that they are feasible in terms of the student's skills and match well with the research question and objectives

- Consider what the findings or contribution of the research may ultimately be

Answering to abovementioned discussion themes will be at an introductory level which can be developed further during candidacy and further meetings. Some student can be ready to answer these questions in the initial meetings and some may need more time to think about them.

These discussions with the student will help the supervisor to understand the student's interest in the topic and gain a greater understanding of their capacity and motivation for the research, as well as assess how well developed their proposal currently is. This process will also 
provide direction for the supervisor to begin the main task of directing and managing the research project (Lee 2008). Note, however, as discussed in the previous section(?), the abilities and capacities of the student also need to be addressed in order to provide a productive and positive start to the candidature.

\section{Negotiating expectations}

Almost all literature on higher degree supervision emphasises the importance of the establishment of roles, responsibilities and expectations with the student from very early on (Aspland et al. 1999).

HDR Student expectations of their supervisor's role vary from student to student, and often this will vary further due to cultural background. The following list are examples of supervisors role which was detailed in Phillips and Pugh (1987, 56-70).

- To be friendly, supportive, interested, invested, open and caring, and be available when needed;

- To ensure a research culture and a caring environment;

- To ensure the facilities are available within the institution to undertake the research;

- Guidance in respect of student initiatives and individual needs and desires;

- To provide regular and quality feedback after having read their work before meeting;

- That any feedback is in a constructively critical format;

- To have a detailed understanding of the research area and research processes;

- $\quad$ To help the student complete in a timely fashion;

- Be interested in the research and help’s student with information; and

- When meeting there are no interruptions and discussions are completed in a logical and direct exchange of ideas. 
At the start of candidature, expectations and level of expectations need to be clearly outlined by both parties. This will help develop an appropriate and suitable working style for both parties. For example, having a clear expectation on the following area is very helpful.

- Feedback: lead time and turnaround time required for feedback, form of feedback (eg. written, oral, email, track changes, version management), quantity and depth of feedback. Spear (2004) provides a great deal of practical advice on how to discern and respond to student expectations, noting that particular attention is required in negotiating the frequency and nature of meetings; response times to written material; and policies for joint authorship, etc.

Meetings and communications: frequency, length, time, dates, place, how meetings will be run. Preferred methods of contact, days in which we can't be contacted (eg. teaching days), best way to leave messages (mobile, email etc.). These things will vary over the period of the $\mathrm{PhD}$ candidature, but the supervisor's approach in outlining at the outset the protocols and identifying the need to change over the candidature will depend on the success of negotiating the frequency of meetings and communications from outset (Ives and Rowley 2005).

Regular communication with supervisors is a good way to sustain tracking of progress and stay motivated during the course of the $\mathrm{PhD}$ journey. Supervisors have a prime role to track of research journey (Rowarth and Green 2006). The best way to promote communication is to schedule regular meetings and some written material before each meeting (Carson 2007). There is a great danger of not being able to complete their thesis when students are avoiding communication with their supervisor, and/or to submit their work for review and isolating themselves from their department, (Manathunga 2002).

- Intellectual Propoerty: Intellectual property is described as the property of a person's mind or intellect. Intellectual property has many facets such as copyright, patents, authorship, and managing confidentiality within a research project. The management of intellectual 
property is a vital component of every stage of the research process. A major challenge in managing the intellectual property of modern research team is that it represents the property of several intellects (students, supervisors, and third party which found the research). Problem may arise when the various players have different perceptions about the relative value of their contributions to the research. Also, external third bodies supported the research may restrict the rights of research team-including students- to make their findings public because of concern about losing legal right to exclusive use of their intellectual property or to invalidate a future patent. In this issue, the impacts of such restrictions on the students' career need to be carefully explained to students (Carson 2007).

- Authorship: what is an appropriate contribution to a publication to warrant joint authorship, how much support is expected in writing publications? Usually there are some contentions around the authorship of research papers produced through $\mathrm{PhD}$ research, and traditions and expectations around co-authorship vary greatly between disciplines and often there is no policy in that regard. While this can be renegotiated as the candidature progresses and papers are produced, a baseline understanding is necessary.

Clarifying the level of intervention in the student's writing is important to be explained at an early stage. If you want students to be competent writers with developed writing and selfediting skills, this expectation should be shared with students. If you desire to edit student's work at early stage but expect the student to take on this responsibility and develop the required skills later on, you need to ensure the student is aware of this changing role (Carson 2007). Somrtimes it may be appropriate for the student to start writing from the outset in the form of a paper, because this can help the student to develop a coherent story of their research. This expectation needs to be shared right from the start. There are different forms of writing such as note taking, summarizing, conference paper for clarifying their understanding. Note taking or writing a conference paper is a useful tool to reduce the procrastination of students' thesis writing (Kamler and Thomson 2006; Carson 2007). Procrastination is easy if 
they are thinking that they are not ready to write. Therefore, starting with something small (Rowarth and Green 2006) such as reading a paper and taking notes, or by writing a conference paper or research journal paper, or by using mind-mapping or concept mapping is a useful way of facilitating progress (Carson 2007). Simple questions such as the following are very helpful to start writing:

- What do you know that nobody else knows?

- How do you know? What do you know is required to be justified by data.

- What are the implications of this research?

In order for both student and supervisor to ensure a strong relationship during the candidature it is beneficial to examine at the outset the expectations of both the student and the supervisor. This should be informed from the context of the overall candidature and cover everything from contact and involvement, to thesis completion expectations. This is especially significant because supervisors and students can differ in their perceptions of the acceptable balance between guidance and autonomy (Spear 2004; Murphy et al. 2007). As Connell (1985, 38) asserts "supervisors have to draw lines to protect themselves as well as to give the student space to work independently”. For example a supervisor might have very high expectations, like the thesis is to be passed without revisions, setting the expectation that the thesis is to be of the highest quality or the number of publication from thesis.

- Mentorship: recommendations and references, conference recommendations, research and teaching work, pastoral care

- Ethics: Where data collection involves human or animal subjects that requires that ethics approval is granted by the University;

- Intellectual property: The intellectual property rights of the student and the University

- Safety: Occupational health and safety, in the University and in the collection of fieldwork and travel 
- Administration: official administrative requirements (e.g. progress reports, examiners selection, thesis submission format)

The administrative requirements often help in the identification of hurdle requirements and the setting of goals and timelines for student's to meet, for example confirmation and ethics submissions. Although it is expected that goals and the associated timetable will alter throughout the candidature, however, objectives and goals should be discussed and agreed upon at the start (Moltschaniwskyj and Moltschaniwskyj 2007). The use of goals and milestones throughout the candidature gives structure to meetings and helps in providing frequent and timely submission of student's work in order for supervisors to provide feedback and help propel the student through the candidature (Latona and Browne 2001). By having a sense of structure through goals and milestones and the negotiation of supervision protocols detailing expectations and needs, provides the foundations and continuity of a quality relationship between the supervisor and student (Tenant and Roberts 2007).

To promote better relationships between supervisors and students there are several tools available to assist in providing a template for establishing expectations and requirements (Grant and Pearson 2007). For examples, Moses (1985) developed a 'Role perception rating scale' which expanded by James and Baldwin $(1999,15)$ can be used as a useful tool for supervisors to analyse their own expectations, as well as the student's. This tool can be an excellent activity to undertake with the student during the first meeting, which the supervisor and the student mark their beliefs on the scale from one to five. For example, regarding the quality of thesis, if the student chooses the score one means:” The supervisor has direct responsibility for the standard of the thesis “, but if the score 5 to be chosen, it means "The supervisor advises only and leaves all decisions concerning content, format and standards to the student”. The outcome of this scaling can then be discussed for reaching a final agreement on the expectations of the supervisor and student from each other. This agreement then forms the basis of the supervisory contract. The role perception statements that Moses (1985) 
developed is only provide an example which then these could be extended further to detail other elements which a supervisor may require in terms of outlining the roles and responsibilities for themselves and the student.

To find out students' expectations, the following questions could be asked:

- How often do you expect to meet your supervisor and by what means (email, phone, fact to face meeting)?

- What do you think is quality feedback?

- How do you define timely feedback?

- What is your definition of a high quality thesis? For example, should a thesis pass without correction?

- What is your expectation of getting help from your supervisor while you are writing your thesis?

- How much do you expect intervention of supervisor in your personal matter?

- What is your definition of an appropriate contribution to a publication in joint authorship?

- Who has intellectual property (IP) right over the project? This question is important to open a space to discuss if there is an alternative arrangement (with scholarship sponsor or industry) regarding IP.

- Who is responsible for keeping track of hurdle requirements for completing the thesis?

\section{Supervisor Reflection}

At the conclusion of the first meeting the supervisor needs to reflect on various levels about the student: their rapport, the abilities and capabilities of the student, the expectations of student and supervisor and whether the supervisor has the knowledge, skills and capabilities to supervise the student in their chosen research area. Reflective practice is emphasised in teaching as well as in supervision, because it allows awareness through reflection of the 
needs, interests, expectations, issues and potential for improvement. In particular, at the end of the first meeting with the student, a supervisor needs to examine the student's expectations and whether these expectations are achievable, also vice versa, the supervisor's expectations of the student and their ability of to achieve them (Pearson and Kayrooz 2004).

Similar to the following questions which is based on authors' self-reflection on their own supervisory practice could be asked:

- What is the level of my expectation from the student? Is it too much or not? And if the student is not performing in the expected level, how much deviation from the expected level is acceptable? What is the current student's threshold level regarding research? And how to develop it to cross over current barriers in the understanding research concept.

- Who could bring complementary knowledge to the team to cover any gap in the supervisor's knowledge? And to what extent the student thinks the supervisor should be knowledgeable?

- If the student has a psychological problem, am I qualified enough to intervene in students personal issues? At what stage should I refer to appropriate specialist intervention?

\section{Conclusion}

The supervisor-student relationship is at the heart of a complex and quite intimate academic and interpersonal relationship. While numerous best practice frameworks exist, supervision cannot be based on a "one-size-fits-all” approach. It is important to conceive of each student as an individual, and use open and honest communication from the outset to negotiate a pedagogical relationship that is flexible, context-specific and mutually rewarding. The discussion points developed in this paper consolidate much of the current literature and condense it into a useable, practical and adaptable best practice framework that can function as an evolving guide in establishing this kind of relationship from the outset. Over the years, 
certain working styles and student-supervisor relationships will manifest within any one supervisory techniques as a more successful approach.

\section{Acknowledgment}

The authors are very grateful for useful comments and discussion of Dr Robyn Barnacle from the School of Graduate Research of RMIT University and Prof. Paul Slatter, School of Civil, Environmental and Chemical Engineering, for comments and proof reading.

\section{References}

Aspland, T., H.Edwards, J.O'Leary, and Y. Ryan.1999.. Tracking New Directions in the Evaluation of Postgraduate Supervision. Innovative Higher Education 24: 127-147.

Buttery, E.A.,Richter, E.M., and Filho, W.L., 2005, "An overview of the elements that influence efficiency in postgraduate supervisory practice arrangments", international journal of education management 19:7-26Carson, Ed. 2007. Helping students manage their candidacy.In Supervising Doctorates Downunder: Keys to effective supervision in Australia \& New Zealand, C. Denholm \& T. Evans (Eds.), 54 - 61., Melbourne: ACER Press Camberwell.

Connell, R.W. 1985. How to supervise a PhD. Veste 28,no. 2:34-41.

Conrad, L. 2007. Developing the intellectual and emotional climate for students. In Supervising Doctorates Downunder: Keys to effective supervision in Australia \& New Zealand, C. Denholm \& T. Evans (Eds.), 36 - 44. Melbourne: ACER Press.

Cullen, D.J. M.Pearson,L. J. Saha,RH. Sear..1994. Establishing Effective Phd Supervision, Australian Government Publishing Service, Canberra. Accessed 8/10/10 at http://www.dest.gov.au/archive/highered/eippubs/230/230_full.pdf

Deem, R. and K.J Brehony,2000. Doctoral Students' Access to Research Cultures-are some more unequal than others? Studies in Higher Education 25,no.2: 149-165. 
Grant, B. 2000. Quality in postgraduate research: Making ends meet. In Pedagogical issues in research education. M. Kiley \& G. Mullins. (Eds), 31-34.Advisory Centre for University Education, The University of Adelaide.

Grant, B. and M. Pearson. 2007. Approaches to doctoral supervision in Australia and Aotearoa New Zealand In Supervising Doctorates Downunder: Keys to effective supervision in Australia \& New Zealand, C. Denholm \& T. Evans (Eds.), 11-18.Melbourne: ACER Press. Gundara, J. 1997. Intercultural issues and doctoral studies. In Working for a Doctorate: a guide for the humanities and social sciences. N. Graves \& V. Varma (eds). 131-151. Routledge London.

Ives, G. and G. Rowley.2005.Supervisor selection or allocation and continuity of supervision: PhD students’ progress and outcomes, Studies in Higher Education 30,no. 5: 535 - 555.

James, R. and G. Baldwin.1999. Eleven practices of effective postgraduate supervisors, Centre for the Study of Higher Education and the School of Graduate Studies, The University of Melbourne, Parkville Australia.

Johnson, L., A.Lee, B.Green .2000. The PhD and the autonomous self: gender, rationality and postgraduate pedagogy. Studies in Higher Education 25, no.2: 135-147.

Latona, C and M. Browne, 2001. Some factors associated with completion of research higher degrees, Canberra: DEST (Department of Education, Science and Training (Austria)

Lee, A. 2008. How are doctoral students supervised? Concepts of doctoral research supervision, Studies in Higher Education 33,no. 3: 267 -281.

Leonard, D. 2001. A woman's guide to doctoral studies, Buckingham,: Open University Press.

Leonard, D. 1997. Gender issues in doctoral studies. In Working for a Doctorate: a guide for the humanities and social sciences. N. Graves \& V. Varma (eds). 152-183. Routledge London. 
Manathunga, C. 2002. Detecting and dealing with early warning signs in postgraduate research education: A work-in-progress. In Quality in postgraduate research: Integrating perspectives. G. Mullins (Ed.), 80-88,Canberra: CELTS, University of Canberra.

McCormack, C., et al. 2006. Taking charge: Using personal learning plans. In Supervising Doctorates Downunder: Keys to effective supervision in Australia \& New Zealand, C. Denholm \& T. Evans (Eds.), 76-86. Melbourne: ACER Press.

Malfroy, J. , 2005, Doctoral supervision, workplace research and changing pedagogic practices, Higher Education Research and Development, Vol. 24, No.2,pp.165-178.

Moltschaniwskyj, N. and G. Moltschaniwskyj. 2007. Setting the scene: initiating the supervision relationship, In Supervising Doctorates Downunder: Keys to effective supervision in Australia \& New Zealand, C. Denholm \& T. Evans (Eds.), Ch.5. Melbourne: ACER Press. Moses, I.1985. Supervising Postgraduates. Campbelltown: HERSDA Inc.

Murphy, N., J. D.Bain, and L. Conrad. 2007. Orientations to research higher degree supervision. Higher Education,53: 209-234.

Over, R. et al. 1990. Publication by men and women with same-sex and cross-sex PhD supervision. Higher Education 20, no.4: 381-391.

Pearson, M. and C. Kayrooz,. 2004. Enabling Critical Reflection on Research Supervisory Practice, International Journal for Academic Development 9, no. 1: 99 - 116.

Pearson, M. 1996. Professionalising PhD education to enhance the quality of the student experience. Higher Education 32: 303-320.

Pearson, M., and A. Brew. 2002. Research training and supervision development. Studies in Higher Education 27, no.2: 135-150.

Philips E.M., and D.S. Pugh.1994. How to get a PhD: a handbook for students and their supervisors. Buckingham: Open University Press.

Rowarth J. and P.Green. 2006. Sustaining inspiration and motivation, In Supervising Doctorates Downunder: Keys to effective supervision in Australia \& New Zealand, C. Denholm \& T. Evans (Eds.), 112 - 119. Melbourne: ACER Press. 
Spear R.H.2004.Supervision of research students: responding to student expectations, ANU digital collection: Open University Press.

Taylor, S. and Beasley, N. 2005. A handbook for doctoral supervisors, London:Routledge,.

Tennant, M. \& Roberts, S. 2007. Agreeing to supervise, In Supervising Doctorates Downunder: Keys to effective supervision in Australia \& New Zealand, C. Denholm \& T. Evans (Eds.), Melbourne: ACER Press.

Thompson, D. 2008. Supervising Research Students. In Nursing research: design and methods, R. Watson (Ed.), 157-163. Churchill Livingstone.

Wisker, G.G., V.Robinson, E. Trafford, E.Creighton, and M.Warnes.2003. Recognising and overcoming dissonance in postgraduate student research. Studies in Higher Education 28, no. $1: 99-105$.

Zuber-Skerritt,O. 1996. Action research in higher education: examples and reflections. London: Kogan Page.

The total number of words in the paper (including those in the Abstract and References) is $\underline{5882 .}$ 